\title{
Moral courage in the workplace: moving to and from the desire and decision to act
}

\section{Leslie E. Sekerka and Richard P. Bagozzi*}

Agere sequitur esse - St. Thomas Aquinas

(Action flows from being).

Vaughan (1874)

\section{Introduction}

Why is moral courage in the workplace viewed as the unusual, rather than the norm? If we want to cultivate organizational environments that exhibit moral strength, we must consider how courage can be exercised in daily organizational life, as an action that can be achieved by everyone. To explore this notion, we see a need to develop additional understanding of how people determine whether or not they will act in a morally courageous way when faced with an ethical challenge. While existing theory sheds light on various aspects of ethical decision making, missing from the literature is an examination of how emotions, automatic responses to situational conditions, along with conscious and deliberative thought, work together to help guide this process. Yet to be fully explored are the internal factors and the social influences that accompany them, specifically those that contribute to forming the desire and decision to act with moral courage. We argue that scholarship designed to explain how

\footnotetext{
*Respectively: Assistant Professor, Organizational Behavior and Ethics, Graduate School of Business \& Public Policy, Naval Postgraduate School, Monterey, CA, USA; and Professor of Marketing, Stephen M. Ross School of Business \& Professor of Social and Administrative Sciences, College of Pharmacy, University of Michigan, Ann Arbor, Michigan, MI, USA.
}

this process unfolds will reshape our understanding of moral courage as an action open to self-control, and thus can occur more frequently than the rare event it is often presumed to be. Our depiction of the organizational member's response to an ethical challenge helps take moral courage out of the extraordinary and into the realm of what can be achieved by most people, at least some of the time.

Leading scholars in the area of ethical decision making have put forth an invitation to integrate constructs, topics and issues that span academic fields, taking a cross-disciplinary approach (Payne \& Giacalone 1990, Treviño 1992). We accept this call and propose a process orientation to the study of moral conduct, one that is grounded in the behavioural sciences but mindful of philosophical contributions. Considering the recent focus on positive organizational scholarship (Cameron et al. 2003), we also show how moral courage can be better understood, encouraged and taught, by learning what contributes to organizational moral flourishing. If organizational members are expected to conduct themselves with exemplary standards of ethical behaviour, it is the responsibility of scholars and managers to provide clarity on how to do so effectively. To address this concern we ask, What induces people to act in morally courageous ways as they face an ethical challenge in the workplace? Our starting assumption is that moral courage can be realized and achieved by most organizational members, under certain personal and situational conditions. To build 


\section{Business Ethics: A European Review}

Volume 16 Number 2 April 2007

Figure 1: The path of moral courage: from ethical challenge to action

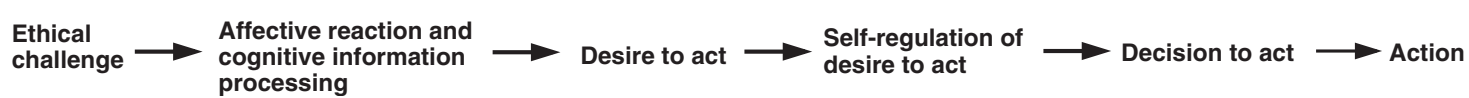

our argument we bring together ideas from ethics, organizational behaviour, philosophy and psychology to understand how individuals act in morally courageous ways as a matter of choice and self-control.

We present a path model (see Figure 1) to depict how affect and cognitions influence choices in higher order decision-making process, where choices are self-controlled and consciously directed. In so doing, we introduce a self-regulatory variable, moving us beyond the largely deterministic characteristics of contemporary models of decision making to encompass aspects of free-will. The theory we develop emphasizes personal choice as central. When an organizational member faces an ethical challenge, referred to by Rest (1986) as recognition of a moral issue, we claim that individuals' experience of different emotions and how they think about competing pressures can lead to their reasons to act - or not to act. This manifests initially as a felt desire to respond in a specific way. The development of a desire to act with moral courage is influenced by personal factors that are, in turn, dependent upon social forces such as organizational directives, social norms, perceived rewards or punishments, social pressure, and other situational and contextual factors. We agree with Rorty's $(1986,1988)$ concern in that the individual must garner the willingness to act as they proceed towards potential engagement and then throughout their decision-making process.

Once a desire to act emerges, the individual is capable of reflecting upon his/her desire to act. We expect that this involves a higher-order decision-making process, as the person decides whether or not to continue to form and bolster this desire, and to act (or not act) on it. Our belief is that this self-regulatory process is governed by an appraisal of whether acting (or not acting) is consistent with the type of person the individual is or wants to be. While similar to features set forth by Jones \& Verstegen Ryan (1997) in their theory of moral approbation, our approach differs in that we propose that first-order desires to act are separate from and precede the moral commitment to act (Rest 1986), which itself is governed by second-order desires or personal moral standards.

The theory we present suggests that before the formulation of a moral commitment, those who are morally courageous are likely to consider whether or not their actions will contribute to personal and organizational flourishing. We show how anticipated emotions, personal values, traits and virtues, along with self-conscious emotions and social identity processes, influence this early appraisal process. Critical to our model is the idea that higher-order decision-making processes are choices. Yet the decisions that the person makes are shaped by their social identity and self-conscious emotions, as well as by the social influences behind them. This constitutes a fresh view, one that expands our limited understanding of moral courage and complements earlier approaches to ethical decision making. This work adds value to existing models of ethical decision making (cf. Ferrell \& Gresham 1985, Hunt \& Vitell 1986, Rest 1986, Treviño 1986, Fritzsche 1991) as we examine the formation of desire and target moral courage as the ultimate action.

We begin our work with a definition of moral courage and then present factors that are expected to influence an individual's desire to act. This includes a consideration of how anticipated emotions may be influential, along with constructs such as subjective and group norms, self-efficacy and outcome expectancies. We introduce the construct of affect towards the means, describing how sentiments towards morally courageous action may bear an impact. Once the desire to act is established, we explain how self-regulation, both automatic and conscious, may influence movement towards the actual decision to act. In all, eight formal propositions are presented to explain how each of these factors (labelled a-i in Figure 2) can influence the progression towards morally courageous action. The mediational (i.e. inter- 
Figure 2: Factors that influence movement to and from the desire and decision to act

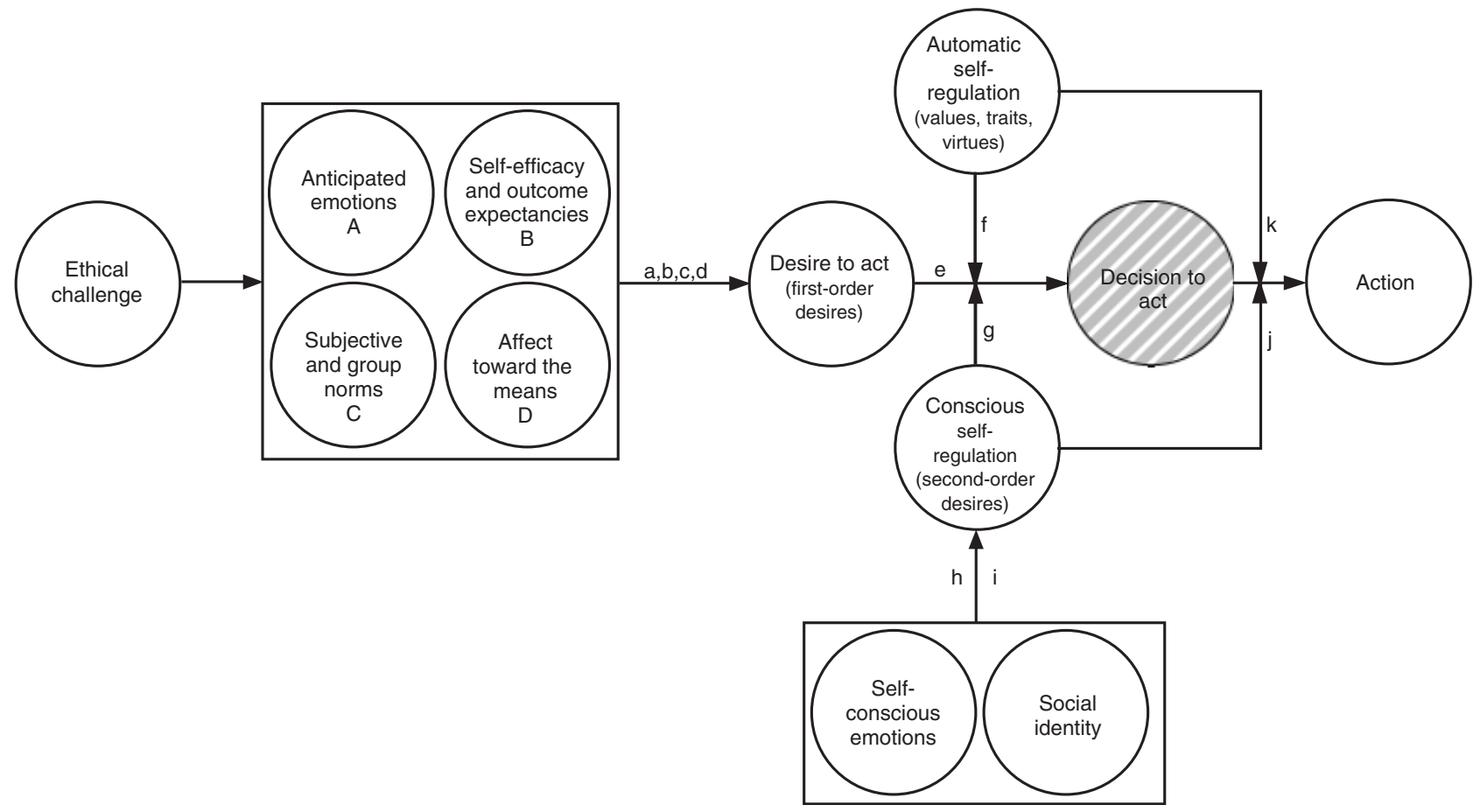

vening) processes and moderating effects (i.e. contingencies that augment or attenuate) are discussed in sequence. Variables (A-D) shown in the combined box in Figure 2 reflect initial discrete responses to an ethical challenge. They function as instigators of the desire to act. While it is beyond the scope of this study to discuss how these variables interrelate, we note that three of these factors (self-efficacy, outcome expectancies, and affect towards the means of goal attainment) combine in a self-reinforcing way to influence the desire to act in a morally courageous manner (see Proposition 4 below). In this study, we specifically identify what may induce the desire to act (a firstorder response) and what may impact the promotion of that desire (a second-order reflection). Our goal is to help explain how every organizational member faces personal choices that promote or curtail their desire to act, as they consider movement towards an act of moral courage.

\section{Moral courage}

Moral behaviour denotes the presence of principles that define right action (Davis \& Frederick
1984). Aristotle (350BC) suggested that courage is both an end and a means in creating comprehensive good (1999: NE 2.6.1103). Our focus is on the internal influences (the means) associated with an individual's reactions, as well as personal ends, such as applying moral standards, as the person moves towards morally courageous action in the workplace. From Aristotelian philosophy we see moral behaviour evolving as a result of setting goals and making choices, or decisions, and establishing moral habits. But, as Aristotle informed us long ago, the first principle of action is not its goal, but rational choice. This work considers how rational choice is based upon desire and goal-directed reason.

Before we begin our description of the decisionmaking process, we must define the desired end state: moral courage. The Oxford English Dictionary notes that the first word, moral, is derived from its Latin root mor, which means custom, habit, routine or practice. Thus, moral persons are those who habitually make judgements regarding the goodness or badness of an action. Individuals make these determinations based on what is good for others and one's relation to others, and routinely make decisions that reflect 


\section{Business Ethics: A European Review \\ Volume 16 Number 2 April 2007}

respect for them. To do this, the individual chooses to conform to the standards of right behaviour as guided by their character and conscience and additionally influenced more by subjective rather than tangible criteria in their decision making. Therefore, to be moral one is guided to judgement based upon convictions of what is considered right, rather than acting only on physical evidence or consequences, or in response to deterministic pressures of one sort or another. The second word, courage, reflects the state or quality of mind or spirit that enables one to face danger, fear or vicissitudes with selfpossession, confidence and resolution. Courage suggests strength of character demonstrated in an act of bravery, in the sense that the person is willing to overcome the threat of harm to self in pursuit of right action. According to the Oxford English Dictionary its root is from the Latin word cor, meaning heart.

Taken together, acts of moral courage are derived from habits of the heart, which can be facilitated by personal volition and self-regulation. Our picture of a morally courageous person is therefore someone who consistently makes decisions in the light of what is good for others, despite personal risk. Cavanagh \& Moberg (1999) suggest that this entails the consideration of right and wrong with a conscious choice for moral good. But moral courage is not merely an automatic behaviour per se; it is a practice, consistently doing what one knows one ought to do (Solomon 1999). This is central to human flourishing (Miller 2005) because, as individuals struggle with their desires and reasoning, sustained fortitude helps them to overcome their own internal strife. Moral courage is a consistent practice of having the virtue of willpower. Moreover, the person is not motivated by other than virtuous ends, because their motives are based solely upon substantive virtues.

In summary, we define moral courage as the ability to use inner principles to do what is good for others, regardless of threat to self, as a matter of practice. We believe that this involves the conscious reflection on one's desires to act, or the lack of such a desire thereof, as one moves towards engagement. We argue that how a person goes about resolving the conflicts between their desires and personal standards is what ultimately leads to a decision to engage in morally courageous behaviour. To explicate our view, we focus on these self-regulatory processes, which are called into play when one faces an ethical challenge. But before we move on to describe the cognitive influencers, we expect that individuals are likely to have an emotional response. Thus, we first explore how affect may influence the desire to proceed.

\section{From emotions to desire}

Aristotle left us with some uncertainty about the function of emotion in exercising moral behaviour. He did provide clues, however, suggesting that a person's ability to be courageous occurs because the 'spirit operates in them' (1999: NE 7.8.1116). Moreover, his account of true courage describes it as perfect harmony between body and soul (Ward 2001). Regardless of his ambiguity, we see threads within his treatise to suggest the presence of affective influence in the expression of moral courage. Aristotle laid the foundation for a theory of moral courage based on emotion when he grounded his work in the concept of virtue and vice, with concerns for pleasure seeking and pain avoidance (1999: NE 2.1.1104, 7.11.1152, 10.1.1172).

Szagun (1992) describes courage as an emotionrelated mental construct. Taking his lead, we begin by examining the influence of one's affective experiences early in the decision-making process. Researchers who describe how people form goals and plans for action typically depict the process as one where people first appraise possible courses of action and then display prudence before engagement. During this period, which may only be a few moments, but may be much longer, cues are received from our affective states that provide information and resources for decision making. Emotions enhance cognitive processes as they signal where to focus attention (Frijda 1986, George \& Brief 1996), facilitate choice making (Bagozzi et al. 2003), and help us to select options, and anticipate situations and their implications (Damasio 1994). Therefore, we begin our examina- 


\section{Business Ethics: A European Review}

Volume 16 Number 2 April 2007

tion with emotions, looking to see how they impact the desire to act in ethical decision making.

Decision making is contingent on both conscious and unconscious criteria and may be influenced by prior emotions experienced during similar encounters. The somatic marker hypothesis (SMH, Damasio 1994) proposes that affective somatic states associated with prior decision outcomes unconsciously serve to guide future decisions by serving as valuations of the personal significance of criteria entering the decision process (see also Hinson et al. 2002). The SMH suggests that learned affective reactions help shape choices and simplify decision making. Damasio and his colleagues have shown how decision making is influenced by signals that arise in bioregulatory processes, including those expressed by emotions. The influence of somatic markers (signals) can occur at multiple levels of cognitive and emotional operations and is essential for establishing motivation. Related to the SMH is the work by Carver \& Scheier (1990, 1998) and Johnson-Laird \& Oately (1989), which describes how emotion is linked with one's sense of progress towards desired goals in a cybernetic system of control. Likewise, as one makes progress in goal pursuit or fails to do so, emotional reactions to these outcomes emerge. They occur in the form of (a) positive affect that functions to sustain goal thriving and (b) negative affect that functions to spur one on or discourage one, depending on specific negative emotional reactions and their intensity and how one copes with them.

Carver \& Scheier's (1998) research suggests that when negative emotions are aroused when an unfavourable outcome is compared with a reference value, they signal to the individual that continued engagement in the activity may not lead to favourable outcomes. Conversely, arousal of positive emotions when a favourable outcome is compared with a reference value may signal that further activity could lead to successful outcomes. In their model of emotion and performance, positive feelings are related to high performance (e.g. doing better than you expect to do) and negative feelings are related to low performance (e.g. doing worse than you expect to do) (Carver et al. 2000). Positive or negative emotional reactions to prior outcomes from past choices will also guide our current responses. To some extent, then, how we construe our present moment depends upon emotions previously experienced as well as currently interpreted. Said differently, outcomes from emotional processes serve to colour and shape our feelings and the subjective experience we presently encounter. In the context of facing an ethical challenge, such reactions will thus influence cognitive associations to past events where similar choices have been made, as well as to the current situation. Therefore, associations, cues and subsequent affective arousals will impact the individual's decision to proceed in ethical decision making.

Anticipated emotions, what we expect to feel in a future situation, may also be influential in decision making (e.g. Bagozzi et al. 1998, Perugini \& Bagozzi 2001). Analogous to counterfactual thinking processes, people have been found to imagine and reflect upon future goal achievement and goal failure. Gleicher et al. (1995) term such thought processes as prefactuals. Imagined goal success leads to positive anticipated emotions (e.g. pride, hope, joy); imagined goal failure leads to negative anticipated emotions (e.g. frustration, disappointment, worry). People are motivated to approach pleasant outcomes and avoid negative outcomes. Hence, anticipated emotions serve to instigate desires to act that are functional for emotional well-being. Taken together, the research on anticipated emotions leads us to propose that there is a relationship between recognition of an ethical challenge and the desire to act with moral courage, which is mediated by anticipated emotions. Thus,

Proposition 1a: The greater the felt positive emotions in anticipation of goal attainment following imagined performance of acts of moral courage, the stronger will be the person's desire to act with moral courage (see path a in Figure 2).

Proposition 1b: The greater the felt negative emotions in anticipation of goal failure following imagined performance of acts of moral courage, the stronger will be the person's desire to act with moral courage (see path a in Figure 2). 


\section{Self-efficacy and outcome expectancies}

Along with emotional reactions, self-efficacy and outcome expectancies are important mental processes in the formation of a morally courageous response. What does the organizational member sense about their ability to control or have influence in a moral challenge? The perception of one's power to act relies upon a belief that the individual has some control over the present circumstances. Picture the organizational member faced with an ethical challenge. Does the individual perceive that they can influence the situation, that they can make a difference (Christensen \& Kohl 2003)? Self-efficacy (Bandura 1982) has been linked with outstanding leadership (Bennis \& Nanus 1985), better leadership performance under stress (Murphy 1992), and is related to work motivation (Gist \& Mitchell 1992). We believe it is also an important contributor to the desire to act with moral courage.

Self-efficacy is a psychological state and refers to one's confidence that one can perform a specific behaviour in a particular situation. It thus differs from the concept of locus of control (e.g. Lefcourt 1992), which is a psychological trait and refers to a general disposition to act consistently across multiple situations. Self-efficacy is similar to the concept of perceived behavioural control, although the latter is measured with items that encompass self-efficacy as well as related concepts (e.g. Ajzen 2002). A closer look at Bandura's work reveals that perceptions of efficacy can enhance or impair motivation and performance in multiple ways, including the kind of activities people choose to engage in (1982) and the effort and persistence exerted to achieve one's goals (Bandura \& Cervone 1986).

Self-efficacy is relevant to moral courage because these types of judgements 'influence not only what skills people perceive themselves to have, but also what they believe they can do with the skills they possess' (Chemers et al. 2000: 268). Such beliefs can affect cognitive processes, eliciting either confidence or debilitating self-doubt (Bandura \& Wood 1989). Chemers et al. (2000) examined dispositional affect and leadership effectiveness and found that self-efficacy is associated with leadership potential and performance. Moreover, self-efficacy may be related to motivation that may affect levels of perseverance in the face of difficulty, which would be beneficial towards stimulating a desire to engage in acts of moral courage. Building on what we know from prior research, we propose that the relationship between recognition of an ethical challenge and the desire to act is mediated by self-efficacy. Hence,

Proposition 2a: The greater the felt self-efficacy towards acts of moral courage, the stronger will be the person's desire to act with moral courage ( see path $b$ in Figure 2).

In terms of the decision maker's experience, selfefficacy refers to a sense of personal control or causation in the decision context. But in addition to self-efficacy, other forces beyond one's control can also be influential. Outcome expectancies are judgements of the likelihood that an action will lead to a desired goal and take into account events under, as well as beyond, one's control. As Carver \& Scheier (1998: 204-205) point out, outcome expectancies can be more determinative of action than self-efficacy because they, in a sense, represent the results of judgements based upon the effects of personal agency and the effects of forces outside of one's personal agency. Interestingly, people often make judgements to act on the basis of the likelihood of a desired outcome happening. As a result, one's expectations of success and/or failure can be important determinants of an urge to act in a way so as to achieve a sought-for goal. Locke \& Latham (1990) recognize the roles of self-efficacy and outcome expectancies in their high performance cycle model of a goal-directed behaviour. We believe this also relates to the relationship between recognition of an ethical challenge and the desire to act, mediated by outcome expectancies. Therefore,

Proposition 2b: The greater the outcome expectancies of success towards acts of moral courage, the stronger will be the person's desire to act with moral courage (see path b in Figure 2). 


\section{Business Ethics: A European Review}

Volume 16 Number 2 April 2007

\section{Subjective and group norms}

Kelman (1974) identified two aspects of social behaviour tied to norms. One is termed compliance, which refers to the tendency of a person to yield to interpersonal pressure and is based on the need for approval. Compliance processes are similar to the effect of subjective norms (i.e. the belief that other people whom one respects feel that one should act), as studied under the theory of reasoned action (Fishbein \& Ajzen 1975) and the theory of planned behaviour (Ajzen 1991). In turn, the bases for felt subjective norms reside in one's normative beliefs. Each person responds to how their significant referents' feel that they should act, where this is weighted by one's motivation to comply with the expectations of those referents. The efficacy of subjective norms has been demonstrated in many contexts, including organization research (e.g. Sheppard et al. 1988, Armitage \& Conner 2001) and in ethical decision making (Jones \& Verstegen Ryan 1997). Thus, we propose that the relationship between recognition of an ethical challenge and the desire to act is mediated by subjective norms. Therefore,

Proposition 3a: The greater the felt subjective norms that support acts of moral courage, the stronger will be the person's desire to act with moral courage (see path $c$ in Figure 2).

Group norms (i.e. shared values or goals among members of a group) are a second aspect of social behaviour tied to norms (Eagly \& Chaiken 1993). Kelman (1974) termed the processes underlying group norms, internalization. Here, we learn that desires or decisions to act are governed by the congruence of one's values with the values of comembers within a group of significance. The selfregulatory aspects of internalization originate through socialization processes, whereby standards of conduct conveyed by significant others help form self-guides for meeting commonly accepted idealized goals (Higgins 1991). The mutuality of group norms finds expression in the norm of reciprocity (Gouldner 1960), where group members react in kind to support and receive benefits provided by co-members. Internalization processes also lead to feelings of personal or moral obligation with respect to the welfare of group members and go beyond returning favours to include the initiation of beneficial actions on behalf of the group and its members (Cialdini et al. 1991, Tyler 1997). Given this understanding, we propose that the relationship between recognition of an ethical challenge and the desire to act is mediated by group norms. As a result,

Proposition 3b: The greater the felt group norms that support acts of moral courage, the stronger the person's desire to act with moral courage (see path $c$ in Figure 2).

We also see the possibility for group norms to support an act of moral courage, but not because they concur with one's personal desires. For example, group pressure to act may influence the person via negative incentives rather than by strengthening one's desires. In such cases, morally courageous actions would unlikely become habit or practice unless, over time, one's desires to act were altered.

Anticipated emotions and outcome expectancies consider the consequences and likelihood, respectively, of goal achievement and are individual determinants of decisions. Self-efficacy constitutes a personal felt power to act. Subjective norms and group norms address different kinds of social pressures to act so as to achieve a goal. In our context of moral courage, the goal in question might be such instances as to right an injustice, to choose between conflicting moral principles, or to ensure human dignity. There is yet another response that falls outside of the consequences of goal achievement or pressures to act so as to achieve a goal. In particular, a person can have an emotional reaction towards the means needed to achieve a goal of moral relevance, as we develop below.

\section{Affect towards means}

We see affect towards the means as independent of the judged value of a goal, normative pressure or self-efficacy per se. To face an ethical challenge requires one to consider not only to act or not to act, but also how to act. Some instrumental acts will be intrinsically enjoyable or lead to pleasant 
consequences. Others may be so noxious or unpleasant as to lead to avoidance. The felt affect in response to the consideration of the possible means supplies additional information to a decision maker on the personal consequences of engaging in goal pursuit. Depending on the polarity and magnitude of emotional reactions towards the means of goal attainment, a decision to employ one means or another will be seen favourably or unfavourably in and of itself.

Affect towards means, to our knowledge, has not been studied systematically in organization research. The only two studies we found of relevance are by Bagozzi et al. (1992) and Bagozzi \& Edwards (2000). The latter study, on health choices, showed that affect towards means had main effects (i.e. direct effects) in situations where impediments to act were weak but interacted with self-efficacy and outcome expectancies to influence action (i.e. the effects occurred only when the three variables combined in a complex manner), when the impediments to act were strong. Because we see ethically challenging situations as demanding and posing risk, they induce strong impediments to act, both internal to the person and characteristic of the organization context itself. Therefore, we propose that the effect of an ethical challenge on the desire to act will be moderated by one's affect towards the means, self-efficacy and outcome expectancies; that is, the effect of an ethical challenge will vary by the degree of felt affect towards the means needed to act, one's selfconfidence that one can perform the means, and one's belief that the means will lead to successful performance of a morally courageous act. In the language of statistics, these variables combine jointly and function nonlinearly, as opposed to the independent, linear effects implied by the other propositions discussed so far. Thus,

\footnotetext{
Proposition 4: The desire to act in response to an ethical challenge will occur to the extent that one feels positively towards the means of acting, has confidence that one can act, and believes that acting will accomplish the desired ends (this occurs as a combination of $B$ and $D$ through path $d$ in Figure 2).
}

\section{Moving from desire to the decision to act}

The desire to act in response to an ethical challenge can be felt in one of two ways. Philosophers differentiate between appetitive and volitive desires, where the former is an automatic response not based on reasoning per se, whereas the latter is based on deliberative processes (Davis 1984a, b). Apart from the differences in the role of reasoning between the two types of desire, they also differ subtly in the way they are expressed. Synonyms for appetitive desires include craving, hungering, longing, urge and yearning, whereas synonyms for volitive desires encompass want, wish, would like, and covet. The intensity of a volitive desire will be a direct function of anticipated emotions, self-efficacy, outcome expectancies, subjective norms, group norms and affect towards the means needed to achieve a goal. The intensity for our appetitive desire is based on internalized factors, which are often biological; the role of anticipated emotions, self-efficacy, outcome expectancies, subjective norms, group norms, and affect towards means is to free up such latent desires.

Sometimes a desire to act, however arrived upon, will directly lead to a decision to act. This constitutes a deterministic outcome of desire. This deterministic path (see path e in Figure 2) influencing a decision to act occurs when primitive habits, urges, compulsion or impulsivity operate unchecked. This can occur when self-regulation is absent or thwarted, or when first-order desires go unchecked deterministically. In some areas of social psychology, the decision to act is termed an intention to act (e.g. Fishbein \& Ajzen 1975) or an implementation intention (e.g. Gollwitzer 1993). The need to differentiate between the desire to act and the decision to act arises from the dissociation of a desire from an intention or commitment to act (Perugini \& Bagozzi 2004). The direct link between desire and the decision to act can be thought of as either a habitual or compulsive pathway. This path can be activated straightaway, depending on either the degree of one's prior learning in classical conditioning, operant learning or cognitive learning senses. In all of these cases, the effect is deterministic. Thus, 


\section{Business Ethics: A European Review}

Volume 16 Number 2 April 2007

Proposition 5: $A$ direct path from desire to the decision to act with moral courage will occur when individuals act in a predetermined manner (see path e in Figure 2).

In contrast to a direct, deterministic path from desire to decision, a person can self-regulate the influence of desires on decision making in one of two ways. The automatic self-regulation of desires to act (see path $\mathrm{f}$ in Figure 2) occurs as a consequence of a behavioural orientation learned developmentally and often early in life (e.g. Kochanska 1994, Posner \& Rothbart 2000) and is manifest in certain values, traits or virtues. The conscious self-regulation of desire (see path $\mathrm{g}$ in Figure 2) occurs through the wilful application of personal standards to one's felt (first-order) desire and is an example of a second-order desire governing one's first-order desire. We now explain the differences and impact of automatic and conscious influencers that moderate the effect of a first-order desire to act on the decision to act with moral courage.

\section{Self-regulation as a value, trait or virtue}

Personal values can function as automatic selfregulatory mechanisms similar to the role of traits. These internal, pre-established guidelines help direct our responses to situations. Personal values, implicit and explicit, are inherent in our choices and behaviours, and vary depending upon the person and situation (Konrad 1982). Family and peer influence, religious values and personal needs help shape each person and can contribute to how they will act when faced with an ethical challenge in the workplace (Barry 1985). Indeed, research shows that personal values influence moral behaviour (Gautschi 1977, DiBattista 1989). For example, individual difference variables, such as economic value orientation and Machiavellianism, can be positively related to unethical behaviour (Hegarty \& Sim 1979). In other words, our predispositions to behave ethically or unethically are strong predictors of our ethical behaviour. This suggests that we carry with us a preconditioned set of values towards ethical behaviour, which plays an important role that helps to guide decision making. The standards that reside within our moral fibre, as Rokeach (1973) labels personal values, may prove useful in understanding and explaining sensitivity to the ethical dimensions of organizational life (Payne \& Giacalone 1990).

To understand how values, and even virtues, can become habits of choice, let us return to moral courage in the Aristotelian sense (1999: NE 1103a20), as motivated by a desire to do the right thing:

Excellence is an art won by training and habituation. We do not act rightly because we have virtue or excellence, but rather we have those because we have acted rightly. We are what we repeatedly do. Excellence, then, is not an act but a habit.

A modern analogy comes from sportswear maker Nike who, during the initial jogging craze in the 1980s, used the phrase just do it. To build primary demand and gain commercial appeal for consumers to engage in regular exercise, they applied Aristotle's philosophy towards the ethics of good health. That is, they attempted to change behaviour and to make jogging a daily moral choice. In order for moral courage to become a habit of choice, self-regulation must take centre stage to overcome inertia to do nothing, resist temptations, and overcome impediments to action. Living effectively requires that individuals restrain certain impulses and desires, while channeling others in the pursuit of valued goals (Bagozzi 2003).

Self-regulation is described by psychologists as efforts made by an individual to change their response to a given situation (Bandura 1991). So important is this function that Baumeister \& Exline (1999) proposed that self-regulation might be the master virtue, inasmuch as virtues entail overcoming selfish impulses for the sake of the collective. According to Baumeister \& Vohs (2004), self-regulation is the effort made by an individual to initiate or change responses to a given situation. Responses that may be regulated are thoughts, feelings and desires. Self-control is one's ability to alter one's own states and responses. Hence, this function is both key to 


\section{Business Ethics: A European Review}

Volume 16 Number 2 April 2007

adaptive success and central to virtuous behaviour, especially if the latter requires setting aside the pursuit of selfish goals (cf. Baumeister \& Exline 2000).

We also frame and address self-regulation as it originates in personal values and influential personal traits. In an ideal scenario, an individual self-regulates in the course of their decision making automatically - by nature. If exercised regularly over time, personal values (in instrumental and end-state senses) can become second nature to us, evolving into or becoming ingrained as character traits (Rokeach 1973). Personal values are guiding principles in one's life. We believe that if individuals exercise self-regulation regularly, in time they can influence their natural reactions to a situation from being less to more inclined to act in morally courageous ways. The reference to self-regulation as a moral muscle (Baumeister \& Exline 2000) implies that it can strengthen with use. While these factors may be more established for some organizational members than others, we see the potential for further development in most people. Hence, the tendency or likelihood to act in a morally courageous way may be promoted or influenced by increasing the awareness and value of emotional awareness and self-regulation. Moreover, it should be mentioned that personal values (in instrumental and endstate senses) arise through developmental and socialization processes and are often exercised as a response to explicit social influence (Schwartz 1996). They motivate behaviour and justify past action. Taken together, we see that the operation of personal values as automatic self-regulation may have the potential to moderate the effect of the desire to act on the decision to act. That is, to the extent that a person has acquired personal values, traits and virtues to act with moral courage, these individual difference variables can augment or attenuate the influence that a desire to act has on one's decision to so act, depending on whether the value, trait or virtue is consonant or dissonant with the desire. Thus,

Proposition 6: Automatic self-regulation, in the form of personal values, traits and virtues will moderate the relationship between desire and the decision to act with moral courage (see path $g$ in Figure 2).

Whereas we considered self-regulation so far as a value, trait or virtue, suggesting that its effects are largely unconscious and automatic, we now turn to self-regulation as a conscious or controlled way that decision makers transform desires into decisions to act.

\section{Conscious self-regulation}

Central to moral courage may be our ability to respond to and/or alter our emotional and motivational states. That is, we need certain competencies to keep our emotions and motives in perspective, relative to others (Salovey et al. 1993, Feldman Barrett \& Gross 2001). We argue that people, who are aware of their emotions and motives and use them effectively, impose selfregulation to their advantage. To facilitate moral courage our emotions and motives must inform but not overwhelm. Building on Baumeister's selfregulation theory, emotional and motivational awareness coupled with self-control can be used to guide one's choices via incorporation of longrange considerations in decision making. To consider a more systemic view over time, one must keep track of one's emotional and motivational behaviour in the light of the present circumstances. We see that emotional and motivational awareness and the use of emotions and motives, practised alongside self-regulation, are important in responding to an ethical challenge.

Ideas formulated by the philosopher Frankfurt $(1971,1988)$ help us to explain how self-regulation and desires may work together to moderate (i.e. either attenuate or augment) the relationship between the desire to act and the decision to act with moral courage. Frankfurt suggested that people have the capacity for reflective selfevaluation in that they can become aware of their motives, feelings, thoughts and desires. $\mathrm{He}$ proposed that everyone, to different degrees, has the capacity to evaluate their desires and decide whether they want (or do not want) to have these personal desires as they scrutinize them. 


\section{Business Ethics: A European Review}

Volume 16 Number 2 April 2007

Frankfurt termed these mental events secondorder desires. We retain this naming convention, but construe second-order desires in a somewhat different and fuller way than he originally proposed (Bagozzi 2006). We suggest that a decision maker can come to reflect upon a felt (first-order) desire to act in such a way as to cancel, override or postpone further consideration or implementation of the desire to act.

More specifically, we propose that when thinking about one's (first-order) desire to act, one asks oneself such questions as, Am I the kind of person who should have such a desire? Am I the kind of person who acts on this kind of desire? Is the desire I feel consistent with the kind of person I ought or wish to be? Will acting on this desire lead to personal flourishing? and What effect will acting on this desire have on other people important to me, other people whom I may not even know, or society writ large? In a parallel manner, we propose that a decision maker can, in an ethically challenging situation, reflect upon his/ her lack of felt (first-order) desire to act. Here, the person considers whether to embrace, accept or construct a desire to act, and questions analogous to those noted above may be posed self-reflectively (e.g. Is my not feeling a desire to act consistent with the type of person I wish to be?). Given our considerations of self-reflectivity, we frame such expectations as second-order desires and hypothesize that they will moderate (i.e. attenuate or augment) the effect of the first-order desire to act on the decision to act. Hence,

Proposition 7: Conscious self-regulation, in the form of second-order desires, will moderate the relationship between first-order desires and the decision to act with moral courage (see path $g$ in Figure 2).

An additional consideration, not given much attention by Frankfurt, is the question of how second-order desires arise in the first place. Based on recent developments made by emotion psychologists and organizational researchers, we suggest that second-order desires develop and are influenced by two processes, self-conscious emotions and social identity, as developed below.

\section{Self-conscious emotions and social identity}

First, self-conscious emotions serve to shape second-order desires. From a young age, people are socialized to different degrees to feel such selfconscious emotions as empathy, pride, guilt, shame, embarrassment, envy and jealousy (Tangney \& Fischer 1995, Lewis 2000, Tangney 2003). Thus, when confronted with an opportunity and desire to act, a decision maker will find that one or more self-conscious emotions will be activated, depending on the nature of previous developmental experiences and one's history of coping with these emotions. Self-conscious emotions have personal and social connotations and bring a person experiencing them to consider the self as object and self as agent (Barret 1995). Secondorder desires are directly dependent on selfconscious emotions. For example, in the case of pride, this emotion helps to maintain self-esteem, signal to oneself important standards, and facilitate the acquisition of information about the self as object and agent. Pride also shows others that one has achieved valued outcomes, and it promotes competitive motives. Of course, pride must be self-managed in social settings, lest it lead to hubris with negative social consequences (Lewis 2000: 630). The important point for our model of moral courage is that second-order desires respond to the personal and social standards for conduct entailed by positive and negative self-conscious emotions.

Note also that the role of self-conscious emotions that we propose here has some affinity to that proposed in Confucian thought where 'impulsions towards action' are universal tendencies manifest in the virtues of ren (compassion, goodness or benevolence), $y i$ (righteousness, appropriateness), $l i$ (proper behaviour, ritual propriety or good manners), zhi (knowledge or sense of right and wrong) and de virtue (power of moral example) (Richards 1932: 67, Cua 2003). However, the Confucian interpretation of the will in this sense is closer to what we term automatic self-regulation, rather than conscious self-regulation via second-order desires. Self-conscious emotion can thus be seen to play a role in the 
operation of both forms of self-regulation proposed herein.

Another factor that shapes and constrains second-order desires is social identity (Ashford \& Mael 1989, Ellemers et al. 1999, Bergami \& Bagozzi 2000, Dutton et al. 1994). Membership in a group or organization can promote certain values or standards that might be used as criteria in the application of second-order desires. Social identity entails self-awareness of group membership, feelings of attachment and belongingness to the group, and evaluative connotations that one is an important and valued member of the group. As social identity grows, one becomes depersonalized and group or organization standards become paramount. To the extent that the organization can instill standards that promote resolution of ethical challenges, it can help to shape secondorder desires of group members in ways useful for the regulation of desires to act with moral courage. Conscious self-regulation, as influenced by second-order desires, are influential in moving from the desire to the decision to act with moral courage. Thus, we expect the following:

Proposition 8a: Social or self-conscious emotions promote, support or activate second-order desires to act with moral courage and thereby indirectly (through second-order desires) moderate the effect of first-order desires on the decision to act with moral courage (see path $h$ in Figure 2).

Proposition 8b: Social identity promotes, supports or activates second-order desires to act with moral courage and thereby indirectly (through second-order desires) moderates the effect of first-order desires on the decision to act with moral courage (see path i in Figure 2).

\section{Weakness-of-will}

An important overarching issue to consider is the relationship of weakness-of-will (i.e. akrasia) to moral courage (e.g. Rorty 1980, Mele 1987, Charlton 1988, Gosling 1990). Two general forms of weakness-of-will might be identified, depending on whether one considers the failure to avoid doing evil behaviour or to promote doing good behaviour. Charlton (1988: 31) captures important aspects of the former as follows:

... akrasia is not merely desiring what we think bad; it is not even simply doing what we think bad: it is doing what we think bad of our own free will, and that is generally taken to involve being able to refrain.

The notion of akrasia is a longstanding, difficult topic for consideration, and we simply point out two places where it occurs in our framework (i.e. after and before one has made a decision to act; see Figure 2) and what generally must be done to overcome its influence.

By far, the most numerous treatments of akrasia in the literature deal with the failure to act. One instance of the failure to act concerns the inability to implement a decision one has made to act. Between the point in time when one decides to act in a morally courageous manner and would so act, a number of things may conspire to thwart action enactment. Except perhaps in situations where one acts straightaway in an automatic-like manner, following the formation of a decision to act, a variety of external and internal events can intervene between the decision and hoped-for action. For example, a physical impediment might arise to prevent the realization of a planned action. Or perhaps temptation might vie for one's attention and entice one to act in ways contrary to one's original purposes. Unexpected contingencies might serve to confound one's efforts. Likewise, internal impediments might emerge such as fear of failure, lack of confidence in the performance or efficacy of the means needed to achieve a goal, or second thoughts about earlier conclusions, and commitments made before the decision to act. Many additional decisions and commitments must typically be made after a decision to act emerges: for example, mustering the wherewithal to plan and try to act, monitoring progress as one pursues a goal, making needed adjustments in goal striving, maintaining one's commitment and resolve to act as one begins to do so, etc. The performance of a final action or the instantiation of an instrumental behaviour directed at goal attainment can break down. Self-regulatory 


\section{Business Ethics: A European Review \\ Volume 16 Number 2 April 2007}

mental and physical behaviours are obviously needed in such cases (see path $\mathrm{j}$ in Figure 2). Automatic self-regulation might also function in such a case as well (see path $\mathrm{k}$ in Figure 2).

Three other kinds of weakness-of-will have received much less attention in the literature and occur before one makes a decision to act or not to act. Our framework (see Figure 2) seems particularly relevant for pointing out three key issues at hand. The first concerns the case where one is aware of a desire to do evil. To prevent such a desire from coming to fruition, at least two aspects of self-regulation must be manifested. A decision-maker must know what, from the point of view of his/her personal standards, is the right thing to do. Secondly, he/she must be committed to doing the right thing, which in this case is to decide not to do evil. A second case concerns awareness that an action is possible in the face of a moral challenge but that one does not, at the moment, have a desire to act in this regard. For morally courageous action to ensue, a secondorder desire must arise consisting of knowing what is the right thing one should do, in the light of one's personal standards, and being committed to doing what is right. In addition, the decisionmaker must believe that an efficacious way exists for him/her to act and he/she has the ability to so act and no overwhelming obstacles can be discerned. A third and final case is the one where the individual has a first-order desire to act in response to a moral challenge in a morally courageous way. At this point, self-regulation, in the sense of reflection and appraisal on whether one is the kind of person who acts (or should act) in accordance with the felt desire, leads one to decide (or not to decide) to act in concert with that desire to the extent that one holds the requisite personal standards of conduct and is committed to them.

Of course, in all operations of second-order desires any tension between what one feels he or she should (or should not) do, and the felt desire or lack of desire to act must be wilfully resolved, and here is where weakness-of-will plays out. What our framework adds to classic treatments of weakness-of-will is the specification of a decision rule, the general type of content for the rule (i.e. personal standards), and the origins of constraining factors on the content, which are grounded in the specific personal (self-conscious emotions) and social forces (social identity) one is exposed to throughout life.

\section{Conclusion}

Our goal was to suggest that acting in a morally courageous way is subject to self-regulation and thus may become more common than implied by popular discourse. To do so, we considered factors that influence the desire and decision to act with moral courage, when organizational members are faced with an ethical challenge. We described how affect is integrated in the decision-making process when proceeding towards an act of moral courage. This functions through multiple stages via anticipated emotions, affect towards means, desires to act, felt selfconscious emotions and attachment to a group. We explained how initial movement towards morally courageous decision making is also affected by cognitive information processing in the form of self-efficacy, outcome expectancies, and interpersonal and group norms. Moreover, we suggested that social forces shape decisions to act with moral courage, as a function of subjective norms, group norms and social identity.

The model we present depicts how the transition from the desire to a decision to act occurs broadly in one of three ways. A deterministic path (see path e in Figure 2) to a decision to act occurs when desire in the form of primitive habits, urges, compulsion or impulsivity operate unchecked. This can occur when self-regulation is absent or thwarted when first-order desire impetuses go unchecked deterministically. This may happen when one's moral standards are lacking or are at early stages of moral development. An automatic regulation of a first-order desire operates when dispositional values, traits or virtues attenuate or augment the force of a first-order desire (see path $\mathrm{f}$ in Figure 2). A second self-regulatory path (see path $\mathrm{g}$ in Figure 2) functions when a decision maker self-reflectively considers a first-order desire to act and appraises whether it is consistent 
with personal standards and the need for moral excellence. We suggest that these decisions are where individual will and the willingness to act rightly are either elevated to sustain momentum towards action or curtailed. Engaging in an act of moral courage means at times doing what one knows one ought to do regardless of threat or cost. This is, in part, why self-regulation is an essential ingredient in ethical decision making.

While our purpose has been to identify automatic and wilful determinants of the desire and decision to act with moral courage, we would be remiss if we did not underscore that the ultimate goal is to engage in moral action. Regardless of whether this final outcome is to take action or not (no action may be the right course of action in some cases), we acknowledge that desire and decision alone are insufficient. As Aristotle informed us, moral courage is not only knowing what to do, but it is also about acting accordingly (1999: NE 7.10.1152a; 7.11.1152b). Our intention has been to show how movement towards the act can be supported by factors en route to a final actuation. Because our approach implies that when people deal with their desires, this will be accompanied by a series of potentially courageinvolving choice points, our view complements Rorty's (1980, 1986), in that the process calls for a series of acts of self-regulation, self-evaluation and execution of wilful acts.

The multiple points of self-reflection, selfevaluation and self-regulation that the individual faces along the way to action are like 'little mental acts' of moral courage throughout the decisionmaking path. We see these inner process actions as aids in helping a person move forward, culminating in the overt demonstration of moral action. As Rorty (1980) describes the complex structure of this process, one's greatest exposure to failure can be at any point because of weakness of will. Indeed, individuals are vulnerable as they move from one stage to the next. Although the external behavioural action is the final and perhaps most visible outcome, our concern has been to consider the more granular features: the internal mental decision points and actions that influence this impressionable path. Our work has highlighted some of these influences that each person must address throughout the process, in order to achieve the desired end state: morally courageous action.

The model and propositions presented in this study serve as a platform for future research and education for managers and leaders. We went beyond current frameworks by drawing upon contemporary ideas from philosophy, psychology and organization research to describe how affect and cognitions work together with individual and social forces to influence moral courage in the workplace. However, empirical work is needed to test the propositions proposed in this study. Extended study will give educators insights on how to help organizational members learn how to be more aware of their emotions, automatic action tendencies, and the role that second-order desires play in ethical decision making. Ultimately, it is through the functioning second-order desires or the acquisition of virtues that decision makers selfregulate their actions and perform morally courageous behaviours. Advancements in scholarship in this area will ultimately help workers prepare for exercising moral behaviour in multiple contexts, including helping managers to design jobs and create programmes to better prepare employees for everyday and unplanned ethical challenges.

The framework we have provided is germane for managers and leaders who not only face ethical challenges themselves, but who are also responsible for managing people who experience ethical challenges. Moreover, it is relevant for those who are responsible for designing organizations to more effectively foster moral action throughout the course of members' daily worklife activities. Understanding the mechanisms for engagement will instigate learning, and is important for understanding how members' varying emotions, dispositions and values may come into conflict. We take heed from scholars who study courage in the workplace, presenting the concern that programmes to enhance exemplary moral conduct may inadvertently lend credence to extreme actions that can inflict larger and lasting damage (Harris 1999). Fearlessness and overconfidence that verge on rashness are most certainly undesirable. Therefore, the assumption that courage is good for its own sake can be erroneous. Without 


\section{Business Ethics: A European Review \\ Volume 16 Number 2 April 2007}

appropriate care, morally courageous actions may inadvertently tip to excess, thus missing the mark of Aristotle's mean (1999: NE 2.7.1107b). Hence, future research must address the development of moral courage in the workplace, focusing on how to instill balanced habituation and practice in daily worklife activities. As Miller suggests, 'Moral courage is one of those things that can only be properly attained by doing it. To get courage, be courageous' (2005: 26).

While expectations for ethical and moral behaviour continue to be pronounced by organizational leaders, little has been offered by way of helping people understand how to engage in it. This is particularly difficult when organizational norms and processes are not congruent with moral action. Therefore, we must encourage scholars, leaders and practitioners to examine incongruence between organizational values, performance expectations, work processes and demands for professional ethics. In conclusion, this work highlighted factors that help us better understand why people act or do not act in morally courageous ways, but more work is needed to ascertain how work environments should be designed and what managers and workers should do to facilitate the performance of morally courageous actions.

\section{Acknowledgments}

We appreciate the insights offered by Chaplain George Clifford, Dr. Eric Jansen, Dr. John Shank and Dr. Margaret Cording. The authors would like to express their gratitude to the Editor and two referees who provided criticisms and suggestions on two earlier drafts of this paper.

\section{References}

Ajzen, I. 1991. 'The theory of planned behavior'. Organizational Behavior and Human Decision Processes, 50:2, 179-211.

Ajzen, I. 2002. 'Perceived behavioral control, selfefficacy, locus of control, and the theory of planned behavior'. Journal of Applied Social Psychology, 32:1, 1-20.
Aristotle. [350BC] 1999. Nicomachean Ethics. Irwin T. (Trans.). Indianapolis, IN: Hackett.

Armitage, C.J. and Conner, M. 2001. 'Efficacy of the theory of planned behavior: a meta-analytic review'. British Journal of Social Psychology, 40:4, 471-499.

Ashford, B.E. and Mael, F. 1989. 'Social identity theory and the organization'. Academy of Management Review, 14:1, 20-40.

Bagozzi, R.P. 2003. 'Benefits and costs of positive and negative emotions: the role of self-regulation'. In Cameron, K.S., Dutton, J.E. and Quinn, R.E. (Eds.), Positive Organizational Scholarship: 176193. San Francisco, CA: Berrett-Koehler.

Bagozzi, R.P. 2006. 'Consumer action: automaticity, purposiveness, and self-regulation'. In Malkotra, N.K. (Ed.), Review of Marketing Research, Volume 2: 3-42. Armonk, NY: Sharpe.

Bagozzi, R.P. and Edwards, E.A. 2000. 'Goal-striving and the implementation of goal intentions in the regulation of body weight'. Psychology and Health, $15: 2,255-270$.

Bagozzi, R.P., Baumgartner, H. and Pieters, R. 1998. 'Goal-directed emotions'. Cognition and Emotion, $12: 1,1-26$.

Bagozzi, R.P., Baumgartner, H. and Yi, Y. 1992. 'Appraisal processes in the enactment of intentions to use coupons'. Psychology and Marketing, 9:6, 469-486.

Bagozzi, R.P., Dholakia, U.M. and Basuroy, S. 2003. 'How effortful decisions get enacted: the motivating role of decision processes, desires, and anticipated emotions'. Journal of Behavioral Decision Making, 16:4, 273-295.

Bandura, A. 1982. 'Self-efficacy mechanism in human agency'. American Psychologist, 37:2, 122-147.

Bandura, A. 1991. 'Human agency: The rhetoric and the reality'. American Psychologist 46: 157-162.

Bandura, A. and Cervone, D. 1986. 'Differential engagement of self-reactive influence in cognitive motivation'. Organization Behavior and Human Decision Processes, 38:1, 92-113.

Bandura, A. and Wood, R. 1989. 'Effect of perceived controllability and performance standards on selfregulation of complex decision making'. Journal of Personality and Social Psychology, 56:5, 805-814.

Barret, K.C. 1995. 'A functionalist approach to shame and guilt'. In Tangney, J.P. and Fischer, K.W. (Eds.), Self-Conscious Emotions: The Psychology of Shame, Guilt, Embarrassment, and Pride: 25-63. New York: Guilford Press. 


\section{Business Ethics: A European Review}

Volume 16 Number 2 April 2007

Barry, V. 1985. Moral Issues in Business. Belmont, CA: Wadsworth.

Baumeister, R.F. and Exline, J.J. 1999. 'Virtue, personality and social relations: self-control as the moral muscle'. Journal of Personality, 67:6, 1165-1194.

Baumeister, R.F. and Exline, J.J. 2000. 'Self-control, morality, and human strength'. Journal of Social and Clinical Psychology, 19:1, 29-42.

Baumeister, R.F. and Vohs, K.D. 2004. Handbook of Self-Regulation: Research, Theory, and Applications. New York: Guilford Press.

Bennis, W. and Nanus, B. 1985. Leaders: The Strategies for Taking Charge. New York: Harper and Row.

Bergami, M. and Bagozzi, R.P. 2000. 'Self-categorization and commitment as distinct aspects of social identity in the organization: conceptualization, measurement, and relation to antecedents and consequences'. British Journal of Social Psychology, 39:4, 555-577.

Cameron, K., Dutton, J.E. and Quinn, R.E. (Eds.). 2003. Positive Organizational Scholarship: Foundations of a New Discipline. San Francisco, CA: Berrett-Koehler.

Carver, C.S. and Scheier, M.F. 1990. 'Origins and functions of positive and negative affect: a controlprocess view'. Psychological Review, 97:1, 19-35.

Carver, C.S. and Scheier, M.F. 1998. On the SelfRegulation of Behavior. Cambridge: Cambridge University Press.

Carver, C.S., Sutton, S.K. and Scheier, M.F. 2000. 'Action, emotion, and personality: emerging conceptual integration'. Personality and Social Psychology Bulletin, 26:6, 741-751.

Cavanagh, G.F. and Moberg, D.J. 1999. 'The virtue of courage within the organization'. In Pava, M.L. and Primeaus, P. (Eds.), Research in Ethical Issues in Organizations, Volume 1: 1-25. Greenwich, CT: JAI Press.

Charlton, W. 1988. Weakness of Will. Oxford: Blackwell. Chemers, M.M., Watson, C.B. and May, S.T. 2000. 'Dispositional affect and leadership effectiveness: a comparison of self-esteem, optimism, and efficacy'. Personality and Social Psychology Bulletin, 26:3, 267-277.

Christensen, S.L. and Kohl, J. 2003. 'Ethical decision making in times of organizational crisis: a framework for analysis'. Business and Society, 42:3, 328-358.

Cialdini, R.B., Kallgren, C.A. and Reno, R. 1991. 'A focus theory of normative conduct: a theoretical refinement and reevaluation of the role of norms in human behavior'. In Berkowitz, L. (Ed.), Advances in Experimental Social Psychology: 201-214. New York: Academic Press.

Cua, A.S. (Ed.), 2003. Encyclopedia of Chinese Philosophy. New York: Routledge.

Damasio, A.R. 1994. Descartes' Error: Emotion, Reason, and the Human Brain. New York: Grosset/Putnam.

Davis, K. and Frederick, W.C. 1984. Business and Society: Management, Public Policy, and Ethics, 5th Edition. New York: McGraw-Hill.

Davis, W.A. 1984a. 'The two senses of desire'. Philosophical Studies, 45, 181-195.

Davis, W.A. 1984b. 'A causal theory of intending'. American Philosophical Quarterly, 21, 43-54.

DiBattista, R.A. 1989. 'Providing a rationale for ethical conduct from alternatives taken in ethical dilemmas'. Journal of General Psychology, 116:2, 207-214.

Dutton, J.E., Dukerich, J.M. and Harquail, C.V. 1994. 'Organizational images and member identification'. Administrative Science Quarterly, 39:2, 239-264.

Eagly, A.H. and Chaiken, S. 1993. The Psychology of Attitudes. Fort Worth, TX: Harcourt Brace Jovanovich.

Ellemers, N., Kortekaas, P. and Ouwerkerk, J.W. 1999. 'Self-categorisation, commitment to the group and group self-esteem as related but distinct aspects of social identity'. European Journal of Social Psychology, 29:2-3, 371-389.

Feldman Barrett, L. and Gross, J. 2001. 'Emotional intelligence: a process model of emotion representation and regulation'. In Mayne, T.J. and Bonnano, G.A. (Eds.), Emotions: Current Issues and Future Directions: 286-310. New York: Guilford.

Ferrell, O.C. and Gresham, L.G. 1985. 'A contingency framework for understanding ethical decision making in marketing'. Journal of Marketing, 49:3, 87-96.

Fishbein, M. and Ajzen, I. 1975. Belief, Attitude, Intention, and Behavior: An Introduction to Theory and Research. Reading, MA: Addison-Wesley.

Frankfurt, H. 1971. 'Freedom of the will and the concept of a person'. Journal of Philosophy, 68:1, 5-20.

Frankfurt, H. 1988. The Importance of What We Care About. New York: Cambridge University Press.

Frijda, N.H. 1986. The Emotions. New York: Cambridge University Press.

Fritzsche, D.J. 1991. 'A model of decision-making incorporating ethical values'. Journal of Business Ethics, 10:11, 841-852.

Gautschi, T.F. 1977. 'Ethics in change'. Design News, 11, 217-219. 


\section{Business Ethics: A European Review \\ Volume 16 Number 2 April 2007}

George, J.M. and Brief, A.P. 1996. 'Motivational agendas in the workplace: the effects of feelings on focus of attention and work motivation'. In Staw, B.M. and Cummings, L.L. (Eds.), Research in Organizational Behavior: An Annual Series of Analytical Essays and Critical Reviews, Vol. 1: 75109. Oxford: Elsevier Science/JAI Press.

Gist, M.E. and Mitchell, T.R. 1992. 'Self-efficacy: a theoretical analysis of its determinants and malleability'. Academy Management Review, 17:2, 183-212.

Gleicher, F., Boninger, D.S., Strathman, A., Armor, D., Hetts, J. and Ahn, M. 1995. 'With an eye toward the future: the impact of counterfactual thinking on affect, attitudes, and behavior'. In Roese, N.J. and Olson, J.M. (Eds.), What Might Have Been: The Social Psychology of Counterfactual Thinking: 283-304. Mahwah, NJ: Lawrence Erlbaum Associates.

Gollwitzer, P.M. 1993. 'Goal achievement: the role of intentions'. European Review of Social Psychology, $4,141-185$.

Gosling, J.C.B. 1990. Weakness of Will (The Problems of Philosophy). London: Routledge.

Gouldner, A.W 1960. 'The norm of reciprocity'. American Sociological Review, 25:2, 165-178.

Harris, H. 1999. 'Courage as a management virtue'. Business and Professional Ethics Journal, 18:3-4, 27-46.

Hegarty, W. and Sim Jr., H.P. 1979. 'Organizational philosophy, policies, and objectives related to unethical decision behavior: a laboratory experiment'. Journal of Applied Psychology, 64:3, 331-338.

Higgins, E.T. 1991. 'Development of self-regulatory and self-evaluative processes: costs, benefits, and tradeoffs'. In Gunnar, M.R. and Sroufe, L.A. (Eds.), Self Processes and Development: The Minnesota Symposium on Child Development: 125-166. Hillsdale, NJ: Erlbaum.

Hinson, J.M., Jameson, T.L. and Whitney, P. 2002. 'Somatic markers, working memory, and decision making'. Cognitive, Affective, and Behavioral Neuroscience, 24:3, 241-353.

Hunt, S.D. and Vitell, S. 1986. 'A general theory of marketing ethics'. Journal of Macromarketing, 6:1, 5-16.

Johnson-Laird, P.N. and Oately, K. 1989. 'The language of emotions: an analysis of a semantic field'. Emotion and Cognition, 3, 81-123.

Jones, T.J. and Verstegen Ryan, L. 1997. 'The link between ethical judgment and action in organizations: a moral approbation approach'. Organization Science, 8:6, 663-680.
Kelman, H.C. 1974. 'Further thoughts on the processes of compliance, identification, and internalization'. In Tedeschi, J.T. (Ed.), Perspectives on Social Power: 126-171. Chicago, IL: Aldine.

Kochanska, G. 1994. 'Beyond cognition: expanding the search for the early roots of internalization and conscience'. Developmental Psychology, 30:1, 20-22.

Konrad, R.A. 1982. 'Business managers and moral sanctions'. Journal of Business Ethics, 1, 195-200.

Lefcourt, H.M. 1992. 'Durability and impact of the locus of control construct'. Psychological Bulletin, 112:3, 411.

Lewis, M. 2000. 'Self-conscious emotions: embarrassment, pride, shame, and guilt'. In Lewis, M. and Haviland-Jones, J.M. (Eds.), Handbook of Emotion, 2: 623-636. New York: Guilford.

Locke, E.A. and Latham, G.P. 1990. A Theory of Goal Setting and Task Performance. Englewood Cliffs, NJ: Prentice-Hall.

Mele, A.R. 1987. Irrationality: An Essay on Akrasia, Self-Deception, and Self-Control. New York: Oxford University Press.

Miller, R. 2005. Moral Courage: Definition and Development. Washington DC: Ethics Resource Center.

Murphy, J. 1992. 'Entrepreneurial organizations and self-evaluation: learning'. Leadership and Organization Development Journal, 13:5, 28-40.

Payne, S.L. and Giacalone, R.A. 1990. 'Social psychological approaches to the perception of ethical dilemmas'. Human Relations, 43:7, 649-665.

Perugini, M. and Bagozzi, R.P. 2001. 'The role of desires and anticipated emotions in goal-directed behaviors: broadening and deepening the theory of planned behavior'. British Journal of Social Psychology, 40:1, 79-98.

Perugini, M. and Bagozzi, R.P. 2004. 'The distinction between desires and intentions'. European Journal of Social Psychology, 34:1, 69-84.

Posner, M. and Rothbart, M. 2000. 'Developing mechanisms of self-regulation'. Development and Psychopathology, 12:3, 427-441.

Rest, J.R. 1986. 'The major component of morality'. In Kurtines, W.M. and Gerwitz, J.L. (Eds.), Morality, Moral Behavior, and Moral Development: 24-38. New York: Wiley.

Richards, I.A. 1932. Mencius on Mind: Experiments in Multiple Definition. London: John Murray.

Rokeach, M. 1973. The Nature of Human Values. New York: Free Press.

Rorty, A.O. 1980. Explaining Emotions. Berkeley, CA: University of California Press. 
Rorty, A.O. 1986. 'The two faces of courage'. Philosophy, 61, 151-171.

Rorty, A.O. 1988. Mind in Action. Boston, MA: Beacon Press.

Salovey, P., Hsee, C.K. and Mayer, J.D. 1993. 'Emotional intelligence and the self-regulation of affect'. In Wegner, D.M. and Pennebaker, J.W. (Eds.), Handbook of Mental Control: Think About Business: How Personal Integrity Leads to Corporate Success. New York: Oxford University Press.

Schwartz, S. 1996. 'Value priorities and behavior: applying a theory of integrated value systems'. In Seligman, C., Olson, J.M. and Zanna, M.P. (Eds.), The Psychology of Values: The Ontario Symposium, Vol. 8: 1-24. Mahwah, NJ: Lawrence Erlbaum.

Sheppard, B.H., Hartwick, J. and Warshaw, P.R. 1988. 'The theory of reasoned action: a metaanalysis of past research with recommendations for modifications and future research'. Journal of Consumer Research, 15:3, 325-343.

Solomon, R.C. 1999. A Better Way to Think about Business: How Personal Integrity Leads to Corporate Success. New York: Oxford University Press.
Szagun, G. 1992. 'Age-related changes in children's understanding of courage'. Journal of Genetic Psychology, 153:4, 405-420.

Tangney, J.P. 2003. 'Self-relevant emotions'. In Leary, M.R. and Tangney, J.P. (Eds.), Handbook of Self and Identity: 384-400. New York: Guilford.

Tangney, J.P. and Fischer, K.W. (Eds.), 1995. SelfConscious Emotions: The Psychology of Shame, Guilt, Embarrassment, and Pride. New York: Guilford.

Treviño, L.K. 1986. 'Ethical decision making in organizations: a person-situation interactionist model'. Academy of Management Review, 11:3, 601-617.

Treviño, L.K. 1992. 'Moral reasoning and business ethics: implications for research, education, and management'. Journal of Business Ethics, 11:5-6, 445-459.

Tyler, T.R. 1997. 'Why people cooperate with organizations'. Research in Organization Behavior, 21, 201-246.

Vaughan, R.B. 1874. Life and Labors of St. Thomas of Aquinas, (2 Vols., London, 1872). Albany, NY: C. Van Benthuysen and Sons.

Ward, L. 2001. 'Nobility and necessity: the problem of courage in Aristotle's Nicomachean ethics'. American Political Science Review, 95:1, 71-84. 